The education of the optician

This content has been downloaded from IOPscience. Please scroll down to see the full text. 1900 Trans. Opt. Soc. 235

(http://iopscience.iop.org/1475-4878/2/1/305)

View the table of contents for this issue, or go to the journal homepage for more

Download details:

IP Address: 150.135.239.97

This content was downloaded on 07/09/2015 at 04:59

Please note that terms and conditions apply. 


\title{
THE EDUCATION OF THE OPTICLAN.
}

\author{
By W. A. Drxey.
}

Presidential address to the Optical Societ!, March 28th, 1901.

$\mathrm{I}^{\mathrm{T}}$ is a privilege accorded to the President of this Society to address 1 a few words upon a subject of his own choosing to the first meeting of the Society at which he presides. In trying to select a subject which would be of general interest, I have thought that I might venture to invite your attention while $I$ put togethor a few ideas on the subject of the Education of the Optician. The subject is a large one, and I cannot hope to do more than deal with it in very sketchy fashion; but that there may be some order in the remarks which $I$ have to offer, we will begin by constructing a framework on which to hang them. We will first then consider what we mean by an Optician, and what an Optician should know; we will then examine what part of the knowledge and capabilities of the Optisian can be instilled by elucation; and lastly we will enquire what facilities are offered by different schools and institutions for the acquisition of such knowledge.

\section{Definition of an 0ptician.}

Our first task, to define an Optician for the purposes of this paper, is not an easy one. We may begin by dividing him into three classes, the working Optician, the trading Optician, and the academic Optician. If we exclude from our consideration the first and the third, we are left with the trading Optician. But he, unfortunately, is not a simple entity. He may be retail or wholesale, master or assistant, his place of business may be a factory, a warehouse, a retail shop, or any combination of these. His work may be confined to one instrument, or to one class of instruments, or it may be distributed over the whole range of so-called optical instruments, in the large sense which in. cludes thermometers, barometers, and such like. We cannot promote separate enquiries into all these possible ramifications; I think we 
shall best deal with our subject, if we imagine a comprehensive Optician, who deals in everything and does everything that belongs to the optical trade. It will be easy to separate from such an one any branch of the subject that does not concern an individual case.

What then ought the Optician to be, and what to know?

\section{Preliminary Education.}

He should be educated up to a certain point in mathematics, in letters, and in languages. To his mathematical education I would put no limit other than his mental capacity and other opportunities may fix. It is true to say that the more mathematics he has the surer will be his grasp of nearly every quality of the optical instruments in which he deals. But we may take as a minimum the requirements of the Spectacle Makers Company ; the standard is not a high one; a a thorough knowledge of arithmetic, algebra to quadratic equations, and an elementary knowledge of geometry and plane trigonometry ; without so much mathematics it is impossible for the Optician to read the books of his subject intelligently, nor can he carry on his work from day to day without being constantly confronted with questions which demand solution, but which are beyond the limit of his comprehension.

His literary education is, in my view, of secondary importance; but it should be carried to the point of enabling him to speak correctly, and write grammatically. The Optician in the course of his career has to get through a great deal of talking. He spends a considerable portion of his working hours in giving adrice. His words, whether spoken or written, cannot but fail of their proper effect if they are not conveyed in correct form. It is the equal mind, the balanced judgment, induced by the study of letters, which prevent our talk degenerating into quackery; while a correct style will often, in the estimation of the hearer, elevate a platitude to the plane of studied wisdom.

Languages may be regarded as a branch of letters; and I want to lay it down as a counsel of perfection that the Optician should acquire a familiar knowledge of French and German ; firstly, because he should keep himself informed of what is being done in his branch of science in those countries as well as in his own; secondly, because he will find it useful in his trade to be able to correspond directly with foreign manufacturers and customers; and, thirdly, because a young man must learn something, and as an Optician he will find modern languages useful in a variety of ways. 
These three subjects, mathematics, letters, and languages, which I put in the order of their importance, are to be considered as the foundation upon which the Optician will build his technical knowledge; and we must now consider, neglecting for the moment the means of acquiring it, of what this technical knowledge consists.

\section{What the Optician Should Know.}

The Optician should know something about all the instruments in which he deals. He should know how they are made, where they are made, and who makes them. He should know how they are used, what they are used for, and who uses them. He should be able to discriminate between different makes of the same instrument, compare workmanship, efficiency and prices, and advise accordingly. He should know the different qualities of similar imstruments, which quality is better adapted to which kind of work, and advise accordingly. All this be should know, not only of the instruments themselves, but of the apparatus and accessories that belong to them. Let us enumerate some of the instruments in which he deals, and we shall be struck by the interesting variety of these demands. There is the microscopeyou will see that each one is really only a heading,-the telescope, the field glass, the opera glass, the photographic camera, the optical lantern, the barometer, the thermometer, the compass, mathematical instruments, nautical instruments, surveying instruments, and a great variety of others which it is not necessary to recall ; and in addition to these the Optician requires a more specialised knowledge of spectacles, and all that pertains to them. This, in general terms, is the necessary technical knowledge of the Optician.

The inference that I want you to draw from the variety of the technical subjects is the necessity of a sound fundamental education. If you have a thorough comprehension of the common phenomena of light, the laws which govern its reflection, refraction, and dispersion, you have in your grasp the principles of every optical instrument. The necessary technical knowledge, of which you make daily use, is most often an obvious deduction from the properties that are familiar to you. But if these fundamental properties are unknown or half known, you are on a very different footing. In a sense you may know your instrument, and its use ; but you have learnt it from the outside; the labour is great; it differs for each instrument; and moreover that kind of knowledge will probably find you wanting, when anything is demanded of the instrument, which is the least out of the common. 


\section{Technical Knowledge.}

So that we shall do well to build upon the foundation of mathematics, letters and languages a sound knowledge of the common properties of light and their application to optical ins truments. With this equipment the Optician may be considered well prepared for the acquisition of that knowledge of his instruments which will be directly useful. For the acquisition of that knowledge he may still rely to a certain extent upon what is generally implied by the word education. Lectures on special instruments, and especinlly laboratory work at technical institutions, may teach him much. He can also get a good deal of knowledge by his own reading; but for the most part he must rely on his native wit, his energy and enterprise, and the opportunities he has of handling, studying and testing the instruments themselves, using throughout his inrestigations that intelligence which his preliminary studies hare enabled him to appls.

\section{The Value of Intercourse.}

In this connection I would point to the valuable assistance which a society such as ours may render. It is a common-place of history that, in the life of a nation, intercourse, whether friendly or hostile, is a condition of progress. To be isolated is to stagnate. I conceive this as a wide-reaching truth: and I venture to suggest that the many and various opportunities for intercourse offered by this and other societies may be so used as to become a valuable factor in the education of the Optician.

\section{Practical Application of Knowledge.}

It would perhaps be interesting, by taking a specific instance, to trace the origin of what knowledge an Optician makes use of in an ordinary every day transaction. A customer wants a night glass for use on board his yacht. The Optician will discriminate between the different classes of binoculars, and will recommend the Galileo system of lenses on account of its relative luminosity. That advice will be drawn from the intelligent application of his studies to his knowledge of instruments. The glass should have six or twelve lenses; his studies enable him to advise. He must determine the magnifying power. Studies here are only a partial guide; his advice will also depend on the use to which the glass is to be put. He notices that his customer has an exceptionally wide pupil distance. His knowledge of optics and of the 
construction of fieldglasses suggests that advantage should be taken of this condition. The customer enquires as to price. Studies are no use here; he must rely on his trade knowledge. Having secured the order he has to get the glass made. He should know in what worlsshops this can be done, and should discriminate between them. That is trade experience. He must specify the form, material, dimensions and optical qualities of the glass, either in consultation with the workmen, or with a knowledge of the capabilities of the workshop. If, for the sake of price or any other cause, he sends his order to France or Germany, he should be able to write his specification in the language of the country. You will see that the knowledge that enables him to do all this has mostly come by education; althongh, without what I have called trade knowledge, he could not in my opinion talse the order and carry it out properly.

Or, let us take an instance from the work of an Optician trading in a country town. In his neighbourhood is a large brewery or some factory where the microscope is used. His native wit will prompt him to discover the uses to which the instrument is put. His optical studies will teach him the best and most economical form of instrument for the purpose, his applied intelligence will ascertain the best conditions of lenses and light that the instrument should assume, his trade experience will tell him the best maker, or it may be the best makers, for he may get stand of one, objectives of another, and accessories of a third ; and if the orders do not come to him, it will not be his fault, or he may be spurred to fresh efforts by the knowledge that they have gone to some one who has done these things better than he.

I hope I have now said enough to convey to you my conception of what an Optician should know, and what part of his knowledge he may acquire by education. I have failed of my purpose, if I have not shown that education is a necessity; that, though it does not supply everything, it forms the necessary foundation for the superstructure, besides furnishing a good many details of that superstructure itself.

\section{Where to Study.}

It now remains to examine what facilities exist for the acquisition of this knowledge; and in respect of what I have called the fundamental education of the Optician I will at once frankly admit that in my opinion, putting aside consideration of time and money, the best education for an intending Optician is that offered by a good English 
public school. This should be followed up at a university by the further study of mathematics and science. A subsequent year in Germany and six months in France would give the student facility in the two languages, with opportunities for technical study. After which he would start his business career with the best possible fundamental education as its most valuable asset. But I recognise that here and now this advice is for most of you in the nature of a counsel of perfection, though in other countries where education is better organised such a course would not be out of the ordinary range.

Perhaps we shall get a more practical view of our subject if we go to the other extreme and imagine a lad entering upon his business career straight from an elementary school. How is such an one to aequire the knowledge that is necessary to a capable Optician. If he enters an Optician's shop, in whatever capacity, he will have opportunities of handling goods and picking up knowledge; opportunities which are of great value, but by themselves insufficient. He must supplement them with study; and I would advise him till he is eighteen to devote as much as he can of his spare time to the study of mathematics first, and also, if possible, of some literary subject. $\mathrm{He}$ should join a good evening school, preferably at one of the polytechnics or institutes which are within reach of most Londoners, and, I doubt not, of the inhabitants of all our principal towns. At eighteen he should test his knowledge at an examination; the best I know of at present is that of the Spectacle Makers Company. I hope, in time, that the Court of the Spectacle Makers Company will arrange for their examination to be taken piecemeal as a matter of course, as indeed, I believe it can already be taken informally. If the examination is successful, the student Optician should then start on the study of physics in general and optics in particular. He will find courses of lectures at King's College, at the polytechnies, and at various other institutions scattered over the town; but he must discriminate. It is a bold thing to say, but it is my conviction that from the Optician's point of view the ordinary lecture course on physics or on optics is of very little use. It is based on academic requirements. Time and energy are frittered away on branches of the subject that are unimportant, while the really valuable part is disposed of in one or two evenings. I think the reason is a failure to recognise the requirements of the shopkeeper. If $I$ thonght my voice could reach the authorities that organise these matters, I should like to put in a strong plea for the shopkeoping Optician. He is a numerous class, and is as desirous as 
any of studying the technicalities of his trade. The matter may be regarded as one of commercial policy. I can, indeed, conceive of no factor more conducive to the development of commercial enterprise in the trade than the technical knowledge of the shopkeeper. What the Optician chiefly wants is a thorough knowledge of the laws of reflection and refraction. He should know and see the action of lenses and prisms singly and in combination. He should be saturated with the formulæ that pertain to them. And his knowledge should be of a kind, not only to enable him to produce a formula in answer to a question in an examination paper; but it should be of the nature of that possessed by a good workman, who knows his tools, foresees the work each one will do, is familiar with its gocd qualities and its short comings (or, shall I say, aberration), and uses his knowledge almost by instinct, or, at least, without any conscious mentrl effort. Some knowledge the optical student requires of the nature and properties of light, of the problems and phenomena of interference, Jiffraction and polarisation, but for the most part a mere nodding acquaintance with these subjects will suffice; while of the other his knowledge must be intimate and thorough. I should frankly confess that these remarks are based on an experience of the facilities that existed in London some ten or fifteen years ago. I let them stand, for I believe that they are still generally applicable. But it is only right to make an important exception.

\section{The Northampton Institute.}

For the purposes of this paper I have been examining the prospectuses of several polytechnics and institutes, and I am delighted to find at the Northampton Institute a special course of classes for Opticians, which, if one may judge by the syllabus, is exactly what the trading Optician requires. There is a class on applied optics which seems to cover the whole ground; I am tempted to add, and a little bit more ; but I have no doubt that the more abstruse optical subjects bulk more largely in the syllabus than they do in the lectures. However that may be, I would advise students that attend that course to give their first and best attention to that part of the subject which I have already indicated, and until that is thoroughly mastered, to keep the rest at a distance. The laboratory work in connection with this class, organised as it is by our fellow member, Mr. Drysdale, whose work we know and appreciate, ought to be most raluable. Then there is a class on so-called visual optics, a subject for which in my day 
there were no ineans of study other than those which were afforded by the medical schools; and eren then the subject was necessarily approached from a different point of view. In the practical class connected with this course the student should learn methods of lens work connected with spectacles, which every Optician should do for himself, as a chemist weighs and mixes his own drugs, such as centering, setting axes of cylinders and prisms, and so on. In the laboratory he need only study the methods, facility he will get by practice in his cwn shop. He should also find there the best tools and the best methods of performing minor manual work connected with spectacle lenses, as shanking, cutting, edging, drilling, balsaming, greying, etc., so that he can direct these operations at home. I would venture to hold out to the teachers at these classes as the object to aim at, not the manual dexterity of the students, but the familiarising them with the best methods ; e.g., in edging, the quality of the stone and the best working speed. An ideal laboratory of this kind should know and study all methods and tools and advocate the best; it should be fitted with apparatus suitable to small workshops, and even I should like to see its power supplied by a small dynamo, such as could be used by the average Optician.

\section{Lectures on Scientific Instruments.}

But with regard to these Northampton Institute classes, I want especially to call your attention to the course on optical and scientific instruments. The arrangements for this class seem to me altogether admirable, the different instruments are taken seriatim, and laboratory work follows the order of the lectures. One can imagine no course of instruction better adapted to the technical requirements of the Optician. If we may judge by the syllabus, methods of testing instruments are dealt with as well as the principles of their construction. This is as it should be, and I hope the work is carried out practically in the laboratory. I have no doubt but that it is. I would suggest also that so far as possible in the laboratory illustrations of, and experiments in the work expected of each instrument be given, e.g., in connection with the microscope, the more critical work of the physiologist, the pathologist, the petrologist, the analyst, the brewer and others who use the instrument professionally should be actually shown, and apparatus and conditions best adapted to each variety of work studied. If I have anything to add to this note of appreciation it would be in the shape of a suggestion that next year, if the course is repeated, the 
advisability be considered of including among the instruments the barometer and the thermometer with their variants : they form a elass of instruments in which nearly all Opticians deal, and in connection with which a good deal of technical knowledge is desirable.

\section{The S.M.C. and the B.0.A. Exams.}

I have said I think enough to emphasise my high appreciation of the facilities for study that are offered to the Optician by the Northampton Institute. I cannot do better than commend these classes to the notice of those of you who are students, or who control the actions of students present or prospective. Those who are out of reach of the Northampton Institute should acquaint themselves with the nature of these classes, and use whatever influence and opportunity they may have to get similar classes started in their own centres. That way lies prosperity and success to the Optician's trade throughout the country. But it is not sufficient that these facilities should be provided; we must take advantage of them. And in that connection I should like to add a word about the examinations of the Spectacle Makers Company and the British Optical Association. I think from this point of view you see these examinations in their right proportions. It is almost a platitude to say that an examination is of no good in itselt. But we can see that from the point of view of the education of the Optician, these examinations serve two very useful ends. Firstly, they tend to attract to the trade young men with brains, and secondly, and chiefly, they act as incentives to young men that are in the trade to study. The examinations present a certain achievable standard to be worked up to, and, human nature being what it is, the prospect of a definite goal, even though it be elusive, like the carrot to the donkey, acts as an inducement to procced. I say this of the Spectacle Makers Company's examination, and it will explain why some of us are so desirous of keeping the so-called full examination as the standard of success. I say it, too, of the British Optical Association's examination, though with less conviction; for the members of that Association would themselves be the first to admit that their subjects are not so comprehensive, nor from the point of view of general optical education, so useful, as those of the other examination.

Gentlemen, at the commencement of this address I promised a sketchy treatment of my subject; at its conclusion I feel its inadequacy even as a sketch. The subject is a great one, scarcely to be 
dealt with in so short a paper. But perhaps some of you will consider the half hour, during which you have listened to me, not altogether wasted, if I have helped to convince anyone of these three uecessities: The necessity of a technical education to the trading Optician; the reed of a sound fundamental education on which to build the technical education; and, in directing the course of that technical education, the necessity of considering its practical ends. (Loud Cheers.)

The following remarks were made at the conclusion of Mr. Dixey's paper.

Dr. Walmsley : Gentlemen, the President's address is not a subject for discussion, as we know, like a paper; therefore I do not rise for the purpose of criticism, but for a far pleasanter duty, and that is to move a very cordial vote of thanks to our President for the address to which we have jnst listened; and in making this motion I think we may congratulate ourselves upon the fact that he has certainly chosen a subject which is second to none in importance, and one result will be to make the members think over the subjects which have been alluded to. I move that the cordial thanks of this meeting be given to our President for his address, and that it shall be printed in our transactions. (Cheers.)

Mr. Artchison: If you will allow me I should like to have the pleasure of seconding that vote of thanks, particularly because the address of our President to-night is one which is really not open to criticism, as it touches a subject which our previous Presidents have kept entirely clear of. The education of the Optician is undoubtedly the subject which has been the cause of the Spectucle Makers Company taking up the work that they have, and I believe really that was the cause of the formation of the Optical Society. (Hear, hear.) I believe this question of the education of the Optician is the object which we all have at heart, and our President has approached the subject in such a broad spirit, and at the same time he has driven the subject home in such a way that I believe what we have previously done has really only been like throwing seed broadcast. Fortunately, some of those seeds have taken root in the work of the Northampton Institute. But to-night I believe our President has actually planted the seed, the growth of which it will be impossible to stop. With regard to one or two of his points, although, of course, the address is not a subject for discussion, I should like to he allowed to make some comment. As to the education of the Optician, it seems to me that 
one fault at present is that the greater number of the new members of the trade or profession-I prefer to call it trade-seem to have drifted into it unconsciously; it is not a trade that they have been brought up to by their parents. I know there are a certain number of the oldestablished houses who bring up their sons to follow them in the business; but the majority of the new men, those who have passed the examinations of the Spectacle Makers Company, are those who, as it were, have taken up the trade as an afterthought. In regard to the education of the Optician, it is quite a question whether a good retail Optician can be made out of a boy who has passed through a public school and then gone to a University, and, added to that, had a year in France and Germany, because he has then got to the age of two or three-andtwenty. Abroad, things are different, because at the age of twenty or so a man has to pass his two or three years of military service. In England, as a rule by that time a young man going into business has already become settled more or less, and if he has not obtained some practical business experience by the age of twenty, he has a tendency to lose the power of acquiring those habits which are necessary in an ordinary retail business. Consequently, that leads me very much to favour the idea of following up the form of education which we have started in connection with the Northampton Institute and other kindred institutions. It seems to me, after a lad has passed through a public school education, if he has a chance of getting a certain business knowledge part of the day, he can, in his spare time, attend such classes as we have been suggesting, and in this way he will stand a very much better chance of being able to make a successful career, by the combination of a business knowledge and the scientific knowledge which we consider necessary for the training of an Optician. (Cheers.) I have much pleasure in seconding the vote of thanks which has been moved by Dr. Walmsley, and I would ask you, gentlemen, to signify your approval in the usual way. (Applause.)

The Chatrmax : I am very much obliged to you, gentlemen, for the cordial way in which you have accepted the motion. I am afraid my paper was very dry indeed. ("No, no.") But after all, it may have afforded, here and there, an interesting subject for your further consideration. If it meets with your further consideration, and if you will help to thinls out sume of the problems that it suggests, it will have entirely served its purpose. I suppose now that $I$ am in the Chair I ought to be the most formal in the room ; I am very much tempted to discuss oue or two points that have been raised, but I will try and refrain 
from doing so. However, I will mention one little matter, not by way of discussion, but by way of explanation. If the seconder of the motion which you have just carried expressed his agreement with some of the points in my paper, I can hardly, myself, express astonishment. It is a curious thing that about three weeks ago, when I was cudgelling my brains about this address, I received a letter from the gentleman who seconded this motion, a very long one, which I read and replied to to the best of my ability. I then put it away in one of my pockets. I then went on cudgelling my brains, and eventually got my subject together and wrote it out. When I had done that I had a sort of idea that I had read something else on the same subject before, and happening to take hold of this letter I read it again, and was horrified to find that my paper was little more than an amplification of the letter I had received! I merely mention this by the way-I do not want to make this particular gentleman responsible for everything that $I$ have said -(Jaughter) - but I mention it to explain the leniency shown with regard to some of the observations I made in my address. (Cheers.) 